NBER WORKING PAPER SERIES

\begin{abstract}
NONLINEAR TAYATION OF RISKY ASSETS AND INVESTMENT, WITH APPLICATION TO MINING
\end{abstract}

Jeffrey K. Mackie-Mason

Working Paper No. 2631

NATIONAL BUREAU OF ECONOMIC RESEARCH

1050 Massachusetts Avenue

Cambridge, MA 02138

June 1988

This research is part of NBER's research program in Taxation. Any opinions expressed are those of the author and not those of the National Bureau of Economic Research. 
NBER Working Paper \#2631

June 1988

\title{
NONLINEAR TAXATION OF RISKY ASSETS AND INVESTMENT, WITH APPLICATION TO MINING
}

\begin{abstract}
An intertemporal capital asset valuation approach is applied to analyzing the effects of nonlinear taxes on asset values and optimal investment decisions. The method is quite general, and is illustrated both analytically and numerically, The paper studies the effects of nonlinearities in the corporate income tax, including the percentage depletion allowance, on mine values and investment decisions. Although the tax policies are found to have the expected effects on asset values, the effects on investment decisions are sometimes perverse. An increase in the income tax rate may encourage investment; an increase in the depletion allowance subsidy may discourage investment.
\end{abstract}

\author{
Jeffrey Mackie-Mason \\ Department of Economics \\ University of Michigan \\ Ann Arbor, MI 48109-1220
}




\title{
Nonlinear Taxation of Risky Assets and Investment, With Application to Mining
}

\author{
Jeffrey K. MacKie-Mason
}

\section{INTRODUCTION}

It is generally known that nonlinearities, asymmetries, and nondifferentiable kinks can play a substantial and oft-times perverse role in determining the effects of tax policies on behavior. The typical treatment in the literature, however, is to treat policies as symmetric and linear. Nonlinearities sometimes turn interesting questions into intractable problems; but nonlinear effects should not always be ignored.

The combination of nonlinearities in the corporate tax system and significant uncertainty make it difficult to model the impact of tax policies on the value of a firm's assets and its investment decisions. Recently, Gordon [1985], Bulow and Summers [1984], Gordon and Wilson [1986] and others have investigated the efficiency costs from taxing risky assets. Their papers have been primarily concerned with a simple tax on capital income. We emphasize, instead, the effects of some of the actual complexities of corporate taxation, such as asymmetric loss treatment and revenue subsidies.

In this paper we treat asset valuation and investment decisions by mining firms, although the methods employed are generally applicable to a wide range of problems faced by economic agents. The existence of special, nonlinear, tax provisions applicable to mining operations and an unusually high degree of price uncertainty suggest that if the interactions between nonlinear taxes and uncertainty are important, mining should be an especially interesting case. ${ }^{1}$

This a substantially revised version of Chapter 1 from my dissertation. I would like to thank Jerry Hausman, Diderik Lund, Bruce Meyer, Bob Pindyck, Jim Poterba, and two anonymous referees for helpful discusaion and suggentions. Financial support was received from the National Science Foundation and the Alfred P. Sloan Foundation.

i In the conclusion to the paper we briefiy review other papers which specifically treat the valuation of mining resources under uncertainty. The emphasis of this paper on the interaction between nonlinear taxes and uncertainty does not appear in the existing natural resource literature. 
When cash flows from an asset are nonlinear in random variables, we know from Jensen's Inequality that standard discounted expected cash flows will not correctly measure asset value. We apply a general equilibrium model of intertemporal asset valuation to determine equilibrium mine values, and to evaluate optimal investment policy, under different tax regimes. With restrictive assumptions, the method yields analytical results which provide insight into some of the complicated interactions between nonlinear taxes and uncertainty. We then present numerical results for a more general problem which captures several operating characteristics of a mining venture.

In the course of demonstrating a feasible method for analyzing the effects of some nonlinear taxes on asset valuation and risky investment decisions, we present some new results on tax policy effects. For example, although the value of a mine is decreasing in the rate of corporate income taxation, an increase in the tax rate may encourage investment. Investment can be encouraged because of the nonlinearity of tax liabilities in stochastic output price. Firms may delay investment in mines in anticipation of higher future prices. Increasing the corporate tax rate increases tax liability more when prices are high than when they are low, reducing the speculative value of delaying investment.

We also analyze the effects of the percentage depletion allowance (PDA). The depletion allowance is an unambiguous subsidy to the value of mining assets. Nonetheless, while increasing quasi-rents, the PDA subsidy can in fact discourage investment in some mining projects. Increasing the PDA lowers the marginal tax rate when prices are high, without changing the tax rate when prices are low. Thus, an increase in the PDA may increase the expected value of future production sufficiently for firms to delay investments in current production. Further, the depletion allowance may also increase the probability that firms will shut down marginal existing projects. Again, a higher allowance rate provides an incentive for the firm to bear the costs of waiting to produce, against the possibility that price will rise and that the subsidy will be larger.

In Section 2 of the paper we briefly describe the types of taxes that are applied to mining ventures, with emphasis on nonlinearities in the corporate income tax and the percentage depletion allowance. This section motivates the need for more sophisticated valuation techniques than are typically employed. We develop the analytical method in 
Section 3. The method is essentially an application of an intertemporal general equilibrium asset pricing model. Placing the analysis in a continuous-time setting generates feasible statements of the asset valuation and optimal investment problems. We investigate some of the effects of taxes on inset value in this section. Then, in Section 4, we consider the effects of taxes on the optimal investment decision. We also implement a numerical solution to a fairly general valuation problem, which captures many aspects of a realistic mining venture. Section 5 concludes the paper.

\section{TAXATION AND MINING FIRMS}

\section{Overview of Taxes on Mining Firms}

Mining operations have typically attracted a large and specialized set of tax policies. Much of the literature on exhaustible resources has considered the effects of different taxes on mining output and prices, usually in the context of a Hotelling [1931] model with no uncertainty or new investment. ${ }^{2}$ More recently, some authors have begun to investigate taxes on mining under uncertainty, and with new investment. These studies have depended primarily on Monte Carlo-type simulations, with a focus on finding the "best" tax policy from a given set, according to some criterion. ${ }^{3}$

Among the many tax provisions applicable to mining firms is the usual corporate income tax with its provisions for depreciation of tangible capital assets. However, much of the value of mining assets is treated differently than it would be under the standard depreciation rules. Most of the costs of exploring for and developing new mining deposits are labelled as "intangible" costs, and are expensible under the U.S. corporate tax code. The primary asset - the mineral reserves themselves - have traditionally been called a “depletable" asset, and firms take a "depletion" deduction, based on gross revenues, rather than a cost-based depreciation deduction."

Other taxes on mining ventures include bonus and royalty payments, usually for lease rights on nationalized resources; severance or output taxes; property taxes; and, various

2 See, e.g. Burness [1976], and for a survey, Dasgupta and Heal [1979].

3 See, e.g., Gamponia and Mendelsohn [1985] and Virmani [1986].

4 It has long been recognized that depletion allowance rules in the U.S. have little to do with the decline in the economic value of the resource. Further, since the capital gain in firm value when a deposit is discovered is not taxed, the depletion deduction is generally recognized as a policy-motivated subsidy. 
sorts of rent taxes which are intended to tax the rents to mineral resource ownership, without distorting the firm's operating and investment decisions. ${ }^{5}$

We focus on the corporate income tax with a percentage depletion allowance in this paper. To simplify the analysis, we assume that all nondepletable assets are treated as intangibles, and thus are expensed rather than depreciated. For new, risky projects, much of the investment is for exploration and development; so this latter assumption is not entirely unrealistic.

Income taxes on net losses are not refundable, and at best can be carried irto other years to offset postive taxable income in those years. As will be shown below, the PDA creates yet another nonlinearity in tax liabilities. The effect of these nonlinearities can be surprising. We will show that an increase in the income tax rate may actually encourage a firm to undertake an investment, even though the value of the project is decreased.

The percentage depletion allowance (PDA) has long been controversial, while accounting for a fairly large reduction in tax receipts. The Treasury Departrnent recently estimated that repealing the PDA for independent oil and gas producers would save the government $\$ 1.4$ billion in 1986 , and a total of $\$ 12$ billion through 1990 (Clark [1985]). ${ }^{6}$ Since it has been recognized that the PDA is a subsidy, its proponents have argued that is a desirable mechanism for compensating firms for the riskiness of mining, and for providing incentives for investing is these enterprises. ${ }^{7}$ Although the PDA is likely to encourage investment in many cases, investments in some situations will be discouraged. The PDA also distorts operating decisions on existing projects. For instance, the PDA may lead firms to shut down projects earlier than would otherwise be optimal.

\section{The Representative Project}

We take the viewpoint of an individual mining firm making incremental investment decisions under uncertainty. We suppose that there is a known quantity of reserves at a particular site, and the firm owns the right to develop the mine and extract the reserves.

5 Garnaut and Clunies-Ross [1975] present a theoretical treatment of a rent tax; see, e.g., Gamponia and Mendelsohn [1985] for the distortions that feasible rent taxes are likely to introduce.

6 Percentage depletion has not been available to the "major" oil and gas producers since 1975. Percentage depletion is still available to all producers in most hard-rock mining industries.

7 Oil and gas industry lobby ists argued during the recent tax reform debates that the PDA and expensing of intangibles are two of the most important incentives for outside sources to invest in drilling projects. See Glen [1985] and Clark [1985]. 
The firm is uncertain about the future evolution of prices, with that uncertainty increasing as the length of the forecast increases. ${ }^{8}$ We place no restrictions on preferences other than that investors have time-additive, risk-averse expected utility functions.

The firm can develop the mirie at a known and fixed investment cost, $I$. Production technology is such that the firm can produce any amount of output per year up to a capacity constraint, $\bar{q}$. The firm can shut down the mine temporarily, and reopen later if conditions warrant, although in general closing and opening will have a fixed cost. The firm can also abandon a mine. (More general technologies and operating policies can also be valued by the methods presented.)

Price is exogenous but stochastic; its dynamics are described by

$$
d p=\alpha p d t+\sigma p d z
$$

where $z$ is a standard Wiener process with unit variance and zero mean; i.e., $p(t)$ follows an Itô process. ${ }^{9}$ Today's spot price is known, but uncertainty increases the further out the firm forecasts; the variance of $p(s)$ is $\sigma^{2} p^{2}(s-t) .{ }^{10}$ The firm plans to sell its output on the spot market.

For simplicity, we assume that unit production costs are known and constant, $c$. Introducing uncertainty or curvature to the cost function is straightforward. ${ }^{11}$

We will specify the details of the tax code in Section 3; for now we refer to net annual tax liabilities as TAX. The annual cash flows from an existing mine are

$$
(p-c) q-F-T A X
$$

where $F$ represents any fixed costs incurred during the period.

8 In an earlier version of this paper, Mackie-Mason [1984a], geological uncertainty was incorporated in two ways: first, by assuming that there is uncertainty about the total amount of reserves to be discovered; and zecond, by assuming that the unit production cost was uncertain and changing over time. Although some interesting results on the role of geological uncertainty emerged, the qualitative implications for investment decisions were unchanged.

- For an introduction to the mathematies of Itô processes, see Merton [1981].

10 We are ignoring the general equilibrium effects of the PDA by opecifying prices exogenously. It is worth noting however, that equation (1) is consistent with the simple Hotelling rule for exhaustible resource industry equilibrium: set $\sigma=0$ and $\alpha=r$ (the rate of interest), and prices will grow with certainty at the rate of interest.

11 See MacKie-Mason [1984a] for cost uncertainty. 
It will be an object of Section 3 to determine the value of a mining project. It is clear that we cannot simply take the expected discounted value of cash flows as the asset's value. First, since the TAX function is nonlinear, and price is stochastic, the expected value is difficult to calculate; by Jensen's Inequality, the expected value of the function is not simply equal to the TAX function applied to the expected value of price and the other parameters.

More importantly, we allow investors to have general, risk-averse preferences. The appropriate discount rate will not in general be the risk-free rate of interest. As is wellknown, there may not even be a well-defined risk-adjusted rate of discount; each stochastic component of cash flow must be discounted according to its own risk characteristics. Further, since the firm can take operating decisions which may affect the riskiness of cash flows (adjustments in the output rate; shutdown and re-opening), the appropriate rates of discount will in general be endogenous.

Thus, we simply state that the value of an existing mine is $M(\mathbf{x}, t ; \psi)$, where $\mathbf{x}$ is a vector of stochastic state variables, $\psi$ is a vector representing the operating options available to the firm (e.g., shutdown, rate of output, etc.), and $t$ represents calendar time. A value-maximizing firm will have to solve a stochastic dynamic programming problem to chose the operating, or control variables $\psi$ to maximize the value of the existing mine. Then, when considering the value of the ("lease") right to invest in and develop a new mine, we will represent that value as $L(M, I, t)$ The value of the right to develop a mine depends on the value of a developed mine, the investment cost, and calendar time. The optimal investment decision, then, is to choose when to make the investment, $I$, so as to maximize the value of the ownership, or lease right, $L$.

The next section of the paper will present a method for determining the values $M$ and $L$ in a dynamic capital market equilibrium. We will then use the resulting valuation functions to investigate the effects of tax policies on asset value and investment decisions.

\section{VALUING RISKY MINING ASSETS}

\section{An Intertemporal CAPM and the Value of Risky Assets}

Suppose the firm wishes to value an asset which depends on an $(n \times 1)$ vector of st variables, $\mathbf{x}$, and a control policy functional, $\psi \in \Psi, \Psi$ a compact space. (The asset can 
be, for instance, an existing mine, or a lease right to develop a new mine.) We assume that the state variables are generated by a joint Itô diffusion process,

$$
d \mathbf{x}=\alpha(\mathbf{x}, \psi) d t+\mathbf{\Sigma}(\mathbf{x}, \psi) d \mathbf{z}
$$

where $\alpha$ is an $(n \times 1)$ vector-valued function, and $\boldsymbol{\Sigma}$ an $(n \times n)$ matrix-valued function. The instantaneous expectation and covariance of the $x_{i}$ are given by $\mathbf{E}\left(d x_{i}\right)=i(\mathbf{x}, \psi)$ and $\operatorname{Cov}\left(d x_{i}, d x_{j}\right)=\sigma_{i j}(x, \psi)$, respectively.

Define the value of the asset to the firm at time $t$ as $V(\mathbf{x}, t, \psi)$. A firm's shareholders and/or managers may have concave preferences over income lotteries, so the risk characteristics of the project may affect its value to the firm. As a result the correct rate of discount is endogenous and will depend on project characteristics, investor and manager preferences, and the firm's optimal control decisions. Thus, we cannot directly specify the value function, $V(\cdot)$. Rather, we use capital market conditions to determine what the value of the project must be in equilibrium.

We need an intertemporal capital asset pricing model which yields equilibrium in asset markets with taxes on corporate cash flows. If we make the assumptions of Merton [1973b]-essentially those of perfect markets, homogeneous expectations and time-additive von Neumann-Morgenstern investor preferences - then it is possible to generalize Merton's result so that in equilibrium, security returns must satisfy the relationship

$$
\mu_{i}-r=\lambda \sigma_{i M} / \sigma_{M}
$$

where $\mu_{i}$ is the instantaneous expected after-tax rate of return on security $i$; $r$ is the riskfree interest rate; $\sigma_{M}^{2}$ and $\sigma_{i M}$ are the instantaneous covariance of the market portfolio with itself and with security $i$, respectively; and $\lambda \equiv\left(\mu_{m}-r\right) / \sigma_{M} \cdot{ }^{12}$ By adding an assumption of free entry and exit, Constantinides [1978] points out that equation (4) must also hold for investment projects viewed as assets.

12 Equation (4) is just a statement for asset markets of the fundamental principle of no excess returns in competitive equilibriun, which must bold in an intertemporal setting as well as in a static model The results states that in equilibrium, an asset must earn a return equal to the risk-free rate plus a premium for systematic risk. 
Following Constantinides [1978], we can now derive a partial differential equation, the solution of which yields the value of the project. Defining $\Pi^{A T}(x, t ; \psi)$ as the after-tax instantaneous rate of cash flow from the asset, given control policy $\psi$, we can show that $V(\mathbf{x}, \psi, t)$ must solve (subscripts on $V$ indicate differentiation)

$$
\max _{\psi \in \Psi}\left\{\Pi^{A T}-\Gamma V+V_{t}+\sum_{i=1}^{n}\left(\alpha_{i}-\lambda \rho_{i M} \sigma_{i}\right) V_{i}+\frac{1}{2} \sum_{i=1}^{n} \sum_{j=1}^{n} \sigma_{i j} V_{i j}\right\}=0
$$

subject to appropriate boundary conditions, where $\rho_{i M}$ is the instantaneous correlation coefficient between $d z_{i}$ and the market return.

Equation (5) is the fundamental valuation result. Assuming the existence of a unique maximizing control policy $\psi^{*}$, the value of the project can be determined from (5) and the boundary conditions. Parabolic partial differential equations of this sort are often solved numerically in finance applications; for a survey of methods, see, e.g., Geske and Shastri [1985] and Brennan and Schwartz [1978]. For some simple problems, the solution to (5) can be obtained analytically; this will be the case for some of the examples considered below.

Another way of looking at the valuation equation leads to a second solution approach, and suggests the intuition for the valuation method. Suppose a firm whose managers and investors are risk-neutral wishes to value an asset. Let the drift vector and variancecovariance matrix for a stochastic vector $\tilde{\mathbf{x}}$ be $\tilde{\alpha}$ and $\boldsymbol{\Sigma}$. A risk-neutral firm values the project by its discounted cash flows

$$
\tilde{V}\left(\tilde{\mathbf{x}}, t ; \psi^{*}\right)=\max _{\psi} \mathrm{E}_{0} \int_{0}^{\infty} \Pi^{A T}(\tilde{\mathbf{x}}, \psi, u) e^{-+u} d u
$$

where $E_{0}$ is the expectation operator conditional on all information known at time $t=0$. From the theory of stochastic optimal control, we can show that $\tilde{V}$ must satisfy

$$
\max _{\psi}\left\{\Pi^{A T}-r \tilde{V}+\tilde{V}_{t}+\sum_{i=1}^{n} \tilde{\alpha}_{i} \tilde{V}_{i}+\frac{1}{2} \sum_{i=1}^{n} \sum_{j=1}^{n} \sigma_{i j} \tilde{V}_{i j}\right\}=0
$$

subject to the appropriate boundary conditions. Constantinides [1978] noted that if we redefine the state equation, (3), by replacing $\alpha_{i}$ with $\tilde{\alpha}_{i} \equiv \alpha_{i}-\lambda \rho_{i M} \sigma_{i}$, then the two 
valuation equations, (5) and (7), are identical. (It is straightforward to show that the boundary conditions in the two problems are identical.) Thus, capital market equilibrium requires that the firm value a project as if preferences were risk-neutral, subject to replacing the drift vector $\alpha$ with $\tilde{\alpha}$.

This approach makes clear that the valuation method has the effect of requiring that each stochastic component of cash flow be discounted at a rate (possibly endogenous) appropriate to its riskiness. The method can be viewed as "correct" way of calculating a risk-adjusted discounted present value, where each stochastic component gets its own risk-adjusted discount rate. Since the problem can be reduced to an expected discounted cash flow calculation, an alternative solution approach to solving the partial differential equation in (5) is to evaluate (6) analytically or by Monte Carlo methods. In Section 4 we shall discuss instances in which the Monte Carlo approach has advantages over the more direct solution.

We now have two straightforward routes for finding project value: solve equation (5), or replace $\alpha$ with $\tilde{\alpha}$ and solve equation (6). Neither requires us to substantially restrict the firm's treatment of risk. The method is analytically tractable in simple problems, and is well-suited to numerical methods of analysis when more realism is desired. In the remainder of the paper, we will apply the valuation method to analyses of the effects of nonlinear tax policies on risky mining assets and investment decisions.

\section{Statement of Tax Rules and Operating Options}

We assume that the mine produces at a fixed rate of $\bar{q}$ per year. Further, once operating, the mine remains open and in operation until the reserves are exhausted. These simplifications allow us to obtain analy tical results, which permit an intuitive understanding of the interaction between nonlinear taxes and uncertainty. (Section 4 introduces a more flexible operating policy.) We also assume that the quantity of reserves available for extraction from the mine is fixed and known at the date of evaluation. ${ }^{13}$

We will consider two different rules for corporate taxation. The first allows for full loss refunds; i.e., if the firm has a taxable loss in a period, the government refunds the negative tax liability. The second rule, at the other extreme, allows for no loss refunds: the firm

13 See MacKie-Mason [1984a] for various treatments of geological uncertainty. 
never collects negative taxes. The actual U.S. rules fall somewhere in-between, allowing firms to carry losses backwards as offsets to positive taxable income during the previous three years (leading to downward revisions of past tax liabilities, and tax refunds), or to carry losses forward to offset future positive taxable income for up to 15 years. ${ }^{14}$

We assume that all capital expenditures on the mine are either expensible as "intangibles" or are treated as depletable, and subject to the PDA rules. Setting the rate of the depletion allowance to zero for a moment, the tax liabilities under the full-refunds and no-refunds rules are then:

$$
\begin{gathered}
T A X^{F}=\tau(p-c) \bar{q} \\
T A X^{N}=\tau \max [p-c, 0] \bar{q}
\end{gathered}
$$

where $(F, N)$ indicate "full refunds" and "no refunds", respectively. (We have suppressed fixed costs for simplicity.)

The percentage depletion allowance rules essentially state that firms may deduct $100 \delta$ percent of gross income from taxable income, subject to a limitation of 50 percent of net income. However, since the PDA is an voluntary deduction, the firm does not have to subtract $50 \%$ of a negative amount if net income is negative. ${ }^{15}$ The firm's tax liability under the full-refunds rule is then

$$
T A X^{F}= \begin{cases}\tau(p-c) \bar{q}-\tau \min [\delta p \bar{q}, .5(p-c) \bar{q}], & \text { if } p \geq c \\ \tau(p-c) \bar{q}, & \text { otherwise }\end{cases}
$$

This can be conveniently simplified as

14 For many firms, the carryback provision means that they effectively face a full refund rule; as long as their losses in a given year don't exceed the sum of positive taxable income over the previous three years, they obtain immediate tax loss refunds. Interactions with various tax credits and other provisions of the law complicate this somewhat; see Altshuler and Auerbach [1986]. For other firms, who carry large and persistent losses so that sufficient positive income is not likely to be earned for many years, the need to rely on carryforwards means that-after discounting-these flms effectively face something like the no-refunds rule. Auerbach and Poterba [1986] have found that once a firm enters a state of $\operatorname{tax}$ loss, persistence in that state is quite high, and the marginal effective refund rate on tax losses can be relatively low. Other firms fall between these two extremes.

15 I am grateful to David Romer for alerting me to this possibility. 


$$
T A X^{F}=\min \{\tau(p-c) \bar{q}, .5 \tau(p-c) \bar{q}+.5 \tau \bar{q} \max [\hat{p}-c, 0]\}
$$

where $\hat{p}=\frac{(.5-\delta)}{.5} p$. Likewise, the firm's tax liability when there are no loss refunds can be written as

$$
T A X^{N}=\tau \bar{q}\{\max [p-c, 0]-.5(\max [p-c, 0]-\max [\hat{p}-c, 0])\}
$$

The firm's tax liability under the two different rules is illustrated in Figure 1 and in Figure 2. (The horizontal axis is measured in pre-tax net income, but unit costs, $c$, and output, $\bar{q}$, are held constant, so only $p$ is increasing.) Consider Figure 1 , in which the firm receives full loss refunds. Without a PDA, the government taxes the constant fraction $\tau$ of net income. With a PDA, the government takes a lower base fraction, $.5 \tau$, if net income is positive, but when the firm is fortunate (stochastic price, and hence net income, is high) the government takes an additional bite through its contingent claim (the max $[\cdot, \cdot]$ term in $(T A X F)$ ); when net income is negative, the government still refunds the fraction $\tau$. The additional, contingent, claim occurs when $p>p^{*}$, where $p^{*}=\left(\frac{.5}{.5-6}\right) \times c$, from equation $(T A X F)$; that is, when $p$ is sufficiently high that $100 \delta$ percent of gross revenue is less than $50 \%$ of net income. We refer to the difference between total tax take with a PDA and the part due to the linear income tax rate as "cream-skimming". The marginal tax rate when there is no PDA is $\tau$; when there is a PDA, the marginal tax rate is $\tau$ for negative taxable income, and $.5 \tau$ when the taxable income is low, but positive. However, when the state of the world is good (the $\max [\cdot, \cdot]$ term is positive), the government "skims the cream" off the top with a higher marginal rate on net income of $(1-\delta) \tau .{ }^{16}$

To value the mine asset, we now follow one of the two related methods outlined above. We can either substitute the period cash flows into the stochastic Bellman equation, (5), and directly solve this partial differential equation, or recognize that if we modify the stochastic process describing the evolution of prices by replacing $\alpha$ with $\tilde{\alpha}$, the solution to (5) is simply the expected present value of the firm's period cash flows, discounted at the

\footnotetext{
16 Obviously the depletion rate, $\delta$, must be less than .5 .
} 


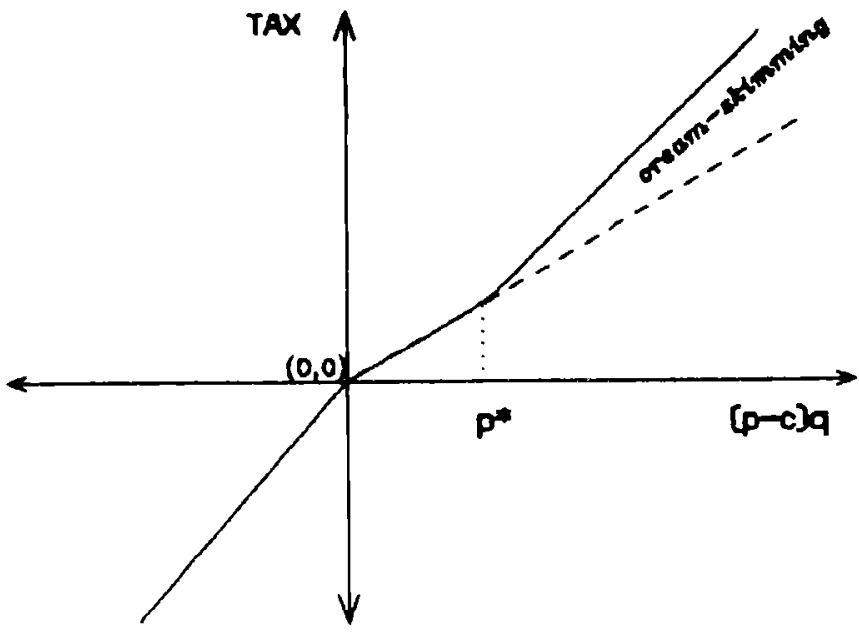

Figure 1. Tax Liabilities with Full Loss Offsets

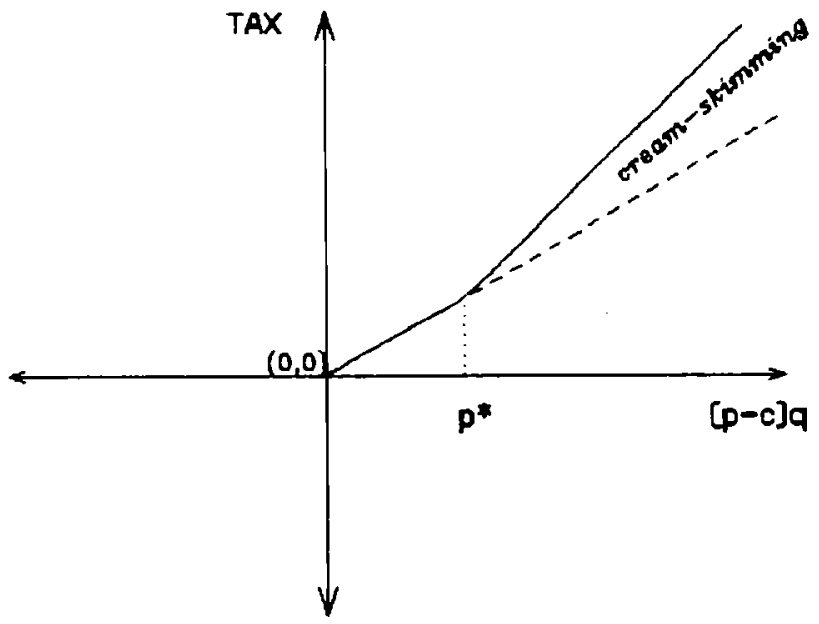

Figure 2. Tax Liabilities with No Loss Offsets

risk-free rate. That is, letting $\Pi^{A T}$ denote the after-tax cash flows, the value of the mine asset is 


$$
M(p, t)=E_{0} \int_{0}^{T} \Pi^{A T}(p, t) e^{-r t} d t
$$

where the appropriate cash-flow formulation is used depending on the loss-refund rule, and with the stocahstic drift in $p$ taken to be $\bar{\alpha}$.

The nonlinearities due to the nondifferentiable $\max [\cdot, \cdot]$ and $\min [\cdot, \cdot]$ terms in the tax liabilities will cause difficulties when we try to evaluate the expected value of cash flows using the valuation rule. However, the same assumptions we adopted to develop the valuation equation enable us to derive an everywhere differentiable, explicit function for the expected present value of the various contingent tax liabilities. Let

$$
W(p, t, c)=\mathrm{E}_{0} e^{-r t} \max [p-c, 0]
$$

where $E_{0}$ is the conditional expectation operator at time zero over the distribution of $p$. $W(p, t, c)$ is the market value at time zero of a claim on the greater of $p(t)-c$ and zero. Since $c$ is known and nonstochastic, this is the same as the value of an option to pay $c$ at time $t$ for an asset whose price is $p(t)$. If $p-c>0$ at $t$, the owner of the option exercises it, paying $c$ and getting an asset worth $p$. If $p-c<0$ at $t$, the option is "out of the money", and the owner does nothing; the option is worthless. This is the description of a European call option; a method for finding its value and a proof of $W(\cdot, \cdot, \cdot)$ 's differentiability is developed in Merton [1976]..$^{17}$ In the full refunds case, for example, the firm "owns a call option on $.5 \tau$ of net income if $p>c$, and the government "owns" a similar call on $.5 \tau$ of $\hat{p}-c$ if $\hat{p}>c .^{18}$

The explicit value of this claim is ${ }^{19}$

$$
W(p, t, c)=e^{-\mu t} p_{0} \Phi\left(d_{1}\right)-e^{-r t} c \Phi\left(d_{2}\right)
$$

where

\footnotetext{
17 For an introduction to options and their use in investment analysis, see Mason and Merton [1986].

$18 \mathrm{Majd}$ and Myers [1984] also view tax liabilites on stachastic income as contingent elaims similar to fin ancial options contracts.

12 This formula can be calculated directly by realizing that $p$ is distributed lognormally, and evaluating the integral expression for the expectation.
} 


$$
\begin{aligned}
\mu & =r-\tilde{\alpha} \\
d_{1} & =\frac{\ln \left[p_{0} / c\right]+\left[r-\mu+\frac{\sigma^{2}}{2}\right] t}{\sigma \sqrt{t}} \\
d_{2} & =d_{1}-\sigma \sqrt{t}
\end{aligned}
$$

We can now write an explicit formulation for the value of an existing, open mine under either of the two corporate tax loss rules:

$$
\begin{aligned}
M^{F}(p, t)=\int_{0}^{T}(1-\tau)\left(p_{0} e^{\tilde{\alpha} t}-c\right) \bar{q} e^{-r t} \\
\quad+.5 \tau \bar{q}\left[\left(p_{0} e^{\tilde{\alpha} t} \Phi\left(d_{1}\right)-c \Phi\left(d_{2}\right)\right)-\left(\beta p_{0} e^{\tilde{\alpha} t} \Phi\left(\hat{d}_{1}\right)-c \Phi\left(\hat{d}_{2}\right)\right)\right] e^{-r t} d t
\end{aligned}
$$

$$
M^{N}(p, t)=\int_{0}^{T}\left\{\left(p_{0} e^{\tilde{\alpha} t}-c\right) \bar{q} e^{-r t}-.5 \tau \bar{q}\left[\left(p_{0} e^{\tilde{\alpha} t} \Phi\left(d_{1}\right)-c \Phi\left(d_{2}\right)\right)+\left(\beta p_{0} e^{\tilde{\alpha} t} \Phi\left(\hat{d}_{1}\right)-c \Phi\left(\hat{d}_{2}\right)\right)\right]\right\} d t
$$

where $\beta=\frac{.5-\delta}{.5}$, and $\hat{d}_{i}$ is equal to $d_{i}$ defined above, with $\hat{p}=\beta p$ substituted for $p . T$ is the number of years required to mine the known reserves at the constant rate $\bar{q}$ per year. In the case of full refunds, the firm pays a base corporate tax rate of $\tau$, whether net income is positive or negative. Then, if net income is positive, the firm gets back a contingent claim equal to half of its tax liability, but the government takes a "cream-skimming" claim equal to the difference between $50 \%$ of net income and $\delta \%$ of gross revenues if price is high enough, $p>c / \beta$.

When there are no loss refunds, the firm gets to keep its net income, less the base corporate tax claim of $.5 \tau$ times positive net income, and less the government's "creamskimming" claim if $p>c / \beta$.

Having found an explicit solution to the value of the stochastic and dynamic cash flows of a mine, we can investigate the effects of the tax policies on mine value, and observe how tax policy interacts with uncertainty. 


\section{Effect of Tax Policy Changes on Asset Value}

Consider first the corporate tax with full loss refunds.

Rosult 1. If the expected discounted pre-tax profits of the mine are positive (negative), then an increase in the (symmetric) corporate tax rate will lower (raise) the value of the mine.

Proof. Differentiating (13) with respect to $\tau$ and rearranging,

$$
\frac{d M^{F}}{d \tau}=\int_{0}^{\tau}\left\{-\left(p_{0} e^{-\mu t}-c e^{-r t}\right) q+.5 q[W(p, t, c)-W(\hat{p}, t, c)]\right\} d t
$$

Period-by-period, the integrand must be negative if expected period profits, $\left(p_{0} e^{-\mu t}-\right.$ $\left.c e^{-r t}\right) q$, are positive, and conversely. ${ }^{20}$ The result follows by taking the integral over the life of the mine.

The result is fairly intuitive. Equation (15) shows that the effect of a corporate tax rate increase is to raise the magnitude of ordinary tax payments (the first term), and also to raise the value of the PDA subsidy to the firm (the second term). Since the PDA subsidy in a given year can never be larger than the a fraction (50\%) of the ordinary tax liability, the first effect dominates. An increase in the tax rate will only benefit mines which are expected to lose money, since loss refunds will provide a net subsidy to the firm, and the subsidy will increase.

It is straightforward to show that an increase in the corporate tax rate always decreases the value of a mine when there are no loss refunds. In this case, the ordinary tax payments increase, and the value of the PDA subsidy increases, but by a proportionately smaller amount. Since only positive taxes are ever paid, the net effect must be to reduce the discounted present value of cash flows, and mine value decreases.

Similarly, we can calculate the comparative static for mine value as the PDA rate changes.

\footnotetext{
20 This is true because the upper limit on $W(p, t, c)$ is equal to expected period profits, and the lower limit on $W(p, t, c)$ is zero, so the difference can never be as great as twice expected profits. By examination, the difference is always positive.
} 
Result 2. The value of a mine is strictly increasing in the percentage depletion allowance rate.

Proof. For the case with full loss refunds,

$$
\frac{d M^{F}}{d \delta}=-\int_{0}^{T} \frac{\partial W(\hat{p}, t, c)}{\partial \delta} d t
$$

Since $\hat{p}=\left(\frac{.5-\delta}{.5}\right) p$, the sign on the partial derivative in the integrand is the opposite of the sign of $\frac{\partial W}{\partial p}$. The value of a European call is increasing in the price of the underlying asset; ${ }^{21}$ the result follows directly.

The intuition for this result can be easily seen by looking at Figure (1). Increasing the PDA rate raises the critical value, $p^{*}$, and lowers the slope of the "cream-skimming" region. Thus, tax liabilities will be weakly lower in all states of the world, and strictly lower when price is high enough. The government's "cream-skimming" is reduced, making the tax liability function less convex; loosely speaking, reducing the convexity of a function decreases its expected value.

The same result is easily derived for the case of no loss refunds, since the PDA subsidy is only operative when net income is positive. ${ }^{22}$

Another way to see the role of uncertainty when evaluating the PDA is to consider the difference between the equilibrium (market) value of the subsidy and the value of the subsidy given an expected price forecast. A naive evaluation of the tax policy might use the latter approach, first forecasting an expected price path, and then, given expected output prices, calculate the value of the subsidy. These are the type of calculations prepared by the U.S. Treasury Department. ${ }^{23}$ However, since the PDA is a nonlinear function of stochastic revenues, this approach violates Jensen's Inequality.

21 See, e.g., Black and Scholes [1973].

22 That the PDA always increases asset value depends importantly on the details of the tax code. If the law required flrms to deduct tax-lose caryforwards from taxable income before the PDA's 50\% of net income limitation is calculated, then the value of marginal mines-those whose asset value is neariy zerio without a PDA-will be decreased by the PDA. Since this change generally lowers the tax rate on loss refunds to $.5 r$, this PDA rule essentially lowers a nondistortionary cash-flow tax on gains and losses to .5r, while giving the government a cream-skimming contingent claim. Lowering the cash-flow tax rate has little effect on marginal asset values, but adding the cream-okmming claim lowers asset values. This case is worked out in greater detail in MacKie-Mason [1984a].

23 See, e.g., Clark [1985]. 
It is easy to see that the value of the PDA subsidy to firms is actually less than the value calculated by the erroneous method. This can be seen in Figure (1). Since the PDA convexifies the government's tax claim on stochastic revenues, the following relationship can be shown:

$$
E[T A X(p)]>T A X(E[p])
$$

The government gets the "cream-skimming" claim when a mine pays off well, but doesn't give anything extra back to the firm when revenues are low.

We now summarize the effects of the PDA on asset value. The realized value of the subsidy is greater as the quasi-rents on a project are greater; i.e., the subsidy increases with realized net income. The subsidy has the smallest effect on the asset value of projects which are marginal. In this sense, it can be said that the PDA is primarily a windfall subsidy to inframarginal projects. Further, the economic value of the subsidy is less than calculations which ignore uncertainty suggest, because if prices fortuitously increase, the government skims the cream off the project.

\section{The Effect of Risk on the PDA Subsidy}

In recent years, the PDA subsidy has been justified as a mechanism for compensating firms for the riskiness of mining, and for providing incentives for investment in mining. ${ }^{24}$ Although there are many different sources and types of risk associated with mining investments, one of the most important is price risk. ${ }^{25}$ We will consider here how increases in price risk affect the value of the PDA subsidy; in Section 4 we investigate the effect of increasing risk on optimal investment decisions.

Whether losses are fully refunded or not, we obtain the following result:

Result 3. If project value is non-increasing in price risk without the PDA, then for suffciently profitable projects (i.e., $p_{0}-c$ large enough), the PDA subsidy decreases as price risk increases.

By the PDA subsidy, we mean the equilibrium value of the difference between future taxes paid with and without a PDA. We will discuss "sufficiently profitable" below.

24 See footnote 1.

25 Bodie and Rosansky [1980] report annual standard deviations in futures prices for several minerals of 25-50\%. 
Proof. (For full tax loss refunds.) Differentiating the function giving a mine's value, (13), by the instantaneous variance of the price process yields ${ }^{26}$

$$
\frac{\partial M^{F}(p, t)}{\partial \sigma^{2}}=\gamma \frac{\partial M^{F 0}}{\partial \sigma^{2}}+.5 \tau \bar{q} c \int_{0}^{T} e^{-\tau t} \frac{\sqrt{t}}{2 \sigma}\left[\phi\left(d_{2}\right)-\phi\left(\hat{d}_{2}\right)\right] d t
$$

where:

$$
\begin{aligned}
\gamma & =\frac{1-\tau+.5 \tau \Gamma(T)}{1-\tau} \\
\Gamma(T) & =\frac{\int_{0}^{T} t e^{-\mu t} \frac{\partial \mu}{\partial \sigma^{2}}\left[\Phi\left(d_{1}\right)-\beta \Phi\left(\hat{d}_{1}\right)\right] d t}{\int_{0}^{T} t e^{-\mu t} \frac{\partial \mu}{\partial \sigma^{2}} d t}
\end{aligned}
$$

and $M^{F 0}$ indicates the value of the mine without a PDA. (The derivation is straightforward, but tedious; see MacKie-Mason [1984].)

Since $d_{1}>\hat{d}_{1}, \beta<1$ and $\Phi(\cdot)$ is bounded above by unity, we have $0<\Gamma(T)<1 .^{27}$ Thus, $\gamma>1$, and the first term of (18) is a multiplier on the aversion to risk without a PDA. Since $\phi(\cdot)$ is the gaussian pdf, for $p_{0}>c$ sufficiently, the second expression in (18) is also negative, and the decline in value of the mine is greater with a PDA than without.

With full loss refunds, the firm pays the ordinary income tax, but receives in return the difference between two contingent claims (see equation (13) and Figure 1). By assumption, the value of the ordinary tax claim is not decreasing in risk (the firm is not price-risk loving). The convexity of the claims causes their value (to the firm and the government, respectively) to increase in risk.

If the initial margin, $\left(p_{0}-c\right)$, is low, then increased risk increases the probability of a project obtaining the PDA at all, since there is no subsidy if net income is negative. In this case, the increase in the value of the firm's contingent claim dominates, and the PDA subsidy may be increasing in risk (i.e., if the second term in (18) is big enough to dominate the multiplier, $\gamma$ ).

26 Although Rothschild and Stiglitz [1970] show that in general variance is not a sufficient proxy for riskiness, Merton [1973a] has shown that when the stochastic procese is Itô, the instantaneous variance is consistent with the Rothschild-Stiglite definition.

27 We have been assuming that investment opportunities are constant through time, so that $\tilde{\alpha}$ and $r$ (hence $\mu$ ) are constants over time. If the signs on $\frac{\partial_{\mu}}{\partial \sigma^{2}}$ could change over time, then $\Gamma<0$ is possible. However, the requirement that $\frac{\partial M^{20}}{\partial \sigma^{2}}<0$ imposes restrictions on $\frac{\partial \mu}{\partial \sigma^{2}}$ that make this unlikely. 
However, if the margin is higher, then an increase in risk primarily increases the probabilitiy of government "cream-skimming"; i.e., the increase in the value of the government's contingent claim dominates. Then, the PDA subsidy decreases with price risk, because $\gamma>1$ and the second term is negative.

So far, we have only considered mines which are already open and operating, and have assumed that the mine will continue operating until exhausted, regardless of profitability. Suppose mine operators have an option to temporarily shut down, or permanently abandon a mine if prices fall too far. Then, we can expect a selection process which results in the portfolio of productive mines being weighted towards those with higher margins, ceteris paribus. In fact, in numerical simulations in which project value is nonincreasing in risk, we find that when a mine has sufficiently high expected profits to remain open and operating, the value of the PDA subsidy declines in price risk. This gives some content to the phrase, "sufficiently profitable": in our calculations, the value of the PDA was decreasing in price risk for any mines sufficiently profitable to be open.

\section{RISKY INVESTMENT DECISIONS}

In this section, we show how the methods described can be extended to the analysis of optimal risky investment decisions. We then investigate, both analytically and numerically, the effect of a corporate income tax and a percentage depletion allowance on risky mining investment decisions. In the numerical examples, we also generalize the description of the operating options available to a mining firm, to increase the realism of the model.

\section{Discussion of the Investment Decision}

Consider a firm which owns the right to exploit the mineral resources in a particular property, and that it costs $I$ to put this property into production. We call the value of this (lease) right $L(p, I, t, T)$, where $T$ is the date on which the right expires. That is, at a price $I$ the firm can buy a producing mine, worth $M(p, R, t ; \psi)$, with $R$ total reserves, and operating policy options $\psi .^{28}$ We continue to assume that reserves are known and fixed, so we suppress the argument, $R$; we also assume for simplicity that the right never expires, so $T$ is infinite.

28 This approach to modeling the investment in a mine has also been adopted by Brennan and Schwarte [1986]. 
For our problem, it is easy to show that there must be some critical initial resource price, $p^{*}$, above which it is optimal for the firm to invest immediately, and below which it is preferable to wait in anticipation of higher prices. Market equilibrium will require that

$$
L\left(p^{*}, t\right)=M\left(p^{*}, t ; \psi\right)-I
$$

Since the firm is free to optimally choose the price at which it will invest, we also know that the following marginal condition is necessary (see Merton [1973a]):

$$
L_{p}\left(p^{*}, t\right)=M_{p}\left(p^{*}, t ; \psi\right)
$$

The fundamental valuation result from Section 2 requires that $L$ also satisfy the following ordinary differential equation (for a lease right that never expires):

$$
\frac{1}{2} \sigma^{2} p^{2} L_{p p}+\tilde{\alpha} p L_{p}-r L=0
$$

The solution to the valuation problem (21) is

$$
\begin{aligned}
& L=a p^{b} \\
& b=\frac{-\left(\tilde{\alpha}-\frac{\sigma^{2}}{2}\right)+\left[\left(\tilde{\alpha}-\frac{\sigma^{2}}{2}\right)+2 r \sigma^{2}\right]^{\frac{1}{2}}}{\sigma^{2}}
\end{aligned}
$$

where $a$ and $p^{*}$ are determined by the necessary conditions (19) and (20).

Before we present the results of some numerical simulations, we again consider our simple analytical example of a mine which, once open, continues producing until all reserves are exhausted. We substitute (L1) into (19) and (20), solve (20) for $a$, and substitute into (19), arriving at (for the full loss offsets case)

$$
\begin{aligned}
& 0=\lambda=\frac{b-1}{b} p \vec{q} \int_{0}^{T}\left\{(1-\tau)+.5 \tau\left[\Phi\left(d_{1}\right)-\beta \Phi\left(\hat{d}_{1}\right)\right]\right\} e^{-\mu t} d t \\
&-c \bar{q} \int_{0}^{T}\left\{(1-\tau)+.5 \tau\left[\Phi\left(d_{2}\right)-\Phi\left(\hat{d}_{2}\right)\right]\right\} e^{-r t} d t
\end{aligned}
$$


To find the effect of various tax parameters on the optimal investment decision, we apply the Implicit Function Theorem to differentiate (22). The resulting expressions are complicated so we discuss some of the results without presenting the calculations.

The optimal investment price is determined on the basis of two values. First, paying the investment price buys the firm a producing mine, which has an asset value. If the value of a producing mine, $M$, is greater than the investment cost, $I$, the investment is potentially desirable.

At the same time, the output price of the project is stochastically changing; typically we assume an upward drift in price, consistent with a stochastic Hotelling equilibrium, such as that derived in Pindyck [1980]. There is some probability that a producing mine will be worth more if production commences tomorrow instead of today; thus there is a value to waiting, or speculating against an abnormally high increase in the production value. The optimal investment price balances the returns to waiting against the profit available from commencing production immediately. For example, if the current price is $p_{t}<p^{*}$, then the value of the lease right is maximized by waiting for price to increase to at least $p^{*}$ before investing in production facilities. ${ }^{29}$

The effects of tax policy on the optimal investment decision are most easily interpreted by describing their impact on the value of waiting and the current profitability of production. By implicitly differentiating (22), the following surprising results can be demonstrated:

Result 4. Increasing the rate of corporate income taxation, $\tau$, can encourage investment, by lowering the optimal critical investment price, $p^{*}$.

Result 5. Increasing the rate of the percentage depletion deduction, $\delta$, can discourage investment.

To describe the first result - that increasing the corporate tax rate may encourage investment - consider a mineral for which the expected rate of (risk-adju. d) price growth,

20 Waiting can be optimal, for example, in an induatry equilibrium with low-cost and high-cost mines. The low cost mines will be developed first, and the high-cost projects later. 
$\tilde{\alpha}$ is relatively high compared to the risk-free return, $r .{ }^{30}$ When the rate of price growth is high, the return to waiting is relatively high, and the optimal investment price will be substantially above the minimal price required to break even on immediate production. An increase in the corporate tax rate decreases the expected compensation for the risk associated with waiting, and the firm is not willing to wait as long before investing in a profitable project. ${ }^{31}$ Thus, even though the value of both the lease right and a producing mine fall as the corporate tax rate increases, investment may be encouraged because the value of production now has risen relative to the value of waiting to produce in the future.

The second result is illustrated by a different case. Suppose that the risk-adjusted rate of price growth is relatively low, and the riskiness of price $\left(\sigma^{2}\right)$ is also low. It is then possible that an increase in the PDA will actually discourage investment, by raising the critical investment price which leads firms to delay production.

When $\tilde{\alpha}$ is low, there is not much gain from waiting to invest; discounting erodes most of the return. In such a case, the optimal investment price will be quite close to the minima! price required to yield an expected profit equal to the required return on the investment cost.

Consider Figure 3. When the PDA is increased, the kink in the tax function is moved outward (the higher $\delta$ means that the $50 \%$ of net income limitation becomes binding at higher prices). In Figure 3, the old optimal investment price now falls below the kink. With the higher PDA, if the firm waits to invest, its expected marginal tax rate on higher prices will be substantially lower than with the lower PDA, and the expected return to waiting is correspondingly higher. At the low optimal investment price, the firm will not make much profit from immediate production, so little is lost by waiting longer to invest to take advantage of the lower tax rate on higher expected future prices.

The interaction between ureartainty and the nonlinearity of the tax system is important in these cases. For instance, in the second example, if price risk is not low, then although

30 That is, the "convenience yield" on the mineral $(\mu=r-\alpha)$-the equilibrium return to holding the mineral now, rather than a futures contract for the mineral - is relatively low, so that most of the equilibrium retum to owning the mineral asset is from market price growth.

31 The immediate profitability of investment is of course also diminished, but when the value to waiting is high, profits-quasi-rents-are relatively high at the optimal investment price, and are still high enough to justify investment even after the tax increase and the lowering of the critical price. 


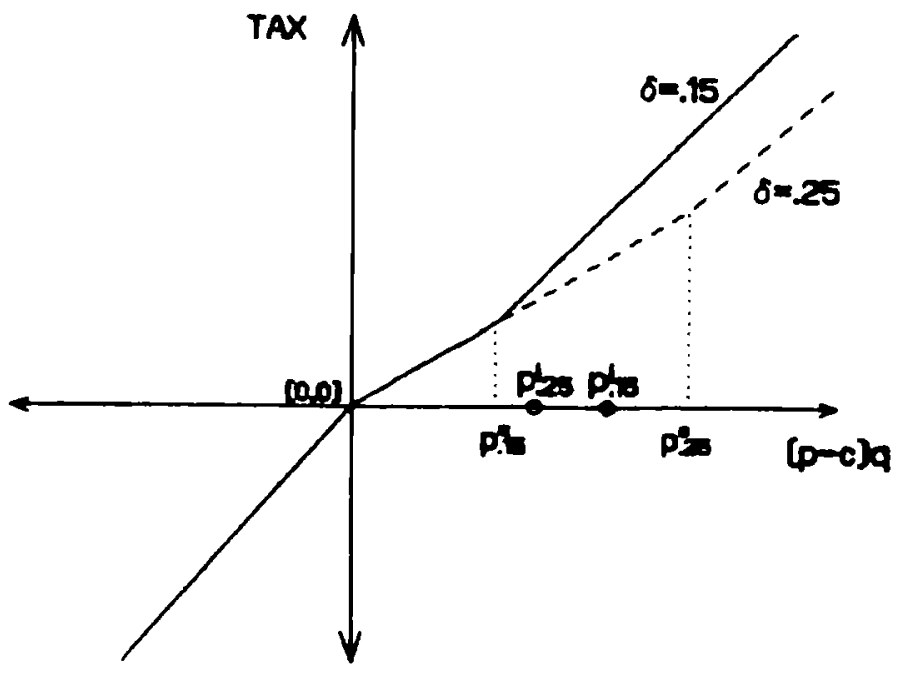

Figure 3. An Increase in the PDA can Discourage Investment

it is more likely that the firm will get higher future PDA deductions, it also is more likely that the project will end up earning losses. The result is that the increased value of waiting from a higher PDA is discounted at a higher rate due to the uncertainty of obtaining the benefits of the lower tax liabilities, and the increase in the value of immediate production may now dominate, leading to greater investment, rather than lower investment.

\section{Numerical Simulations}

Evaluating risky investment decisions is a complicated problem, especially when taxes introduce nonlinearities into cash flows, and when the project is long-lived, with dynamic uncertainty. It will generally be extremely difficult to analytically evaluate the effects of different tax policies, or operating options. The analyses presented above were only feasible because we made severe simplifications in the specification of the mining project and the investment decision.

When more complex conditions are incorporated in the problem, the valuation method described in this paper can be applied numerically. The general method requires the solution to the stochastic Bellman partial differential equation, as in (5), subject to appropriate boundary conditions. The Bellman equation falls into the class of parabolic partial dif- 
ferential equations; numerical solution methods are well-developed for problems in two and even three dimensions. Similar problems are quite regularly solved in finance applications; see, e.g., Geske and Shastri [1985], and Mason [1979] for presentations of numerical methods.

There will be situations in which even the numerical solution of the Bellman equation will be infeasible. For instance, if we were to correctly model corporate income tax loss carryforwards, one of the stochastic state variables on which asset value depended would be the carryforward. In general, it will not be possible to specify a terminal boundary for this state variable; a known terminal boundary is necessary for the backwards recursion solution methods usually applied. However, a Monte Carlo approach may be feasible in some such problems. The Monte Carlo method uses a forward solution, simulating the sample paths of the stochastic state variables, and valuing the asset over a large sample of such simulations. This approach is possible because of the "expected value equivalent" approach outlined in Section 2 above. ${ }^{32}$

We present some results of numerical evaluations in order to demonstrate the feasibility of the valuation method for certain types of problem. We consider an investment in an oil field. Assumptions about production, costs, and rates of return are based on Lund's [1987] analysis of typical North Sea oil fields. ${ }^{33}$ The main assumptions are presented in Table 1.

Although we assume that field output is fixed if producing, we allow the firm to temporarily halt production if prices fall sufficiently, and to restart production if prices rise. Shutdown and reopening have a fixed cost; in addition, maintaining a field during the dormant period also has a (flow) cost. The firm can abandon a field altogether at zero cost, but abandoned fields are never worth reopening.

We present some representative results in Tables 2,3 and 4; Table 2 assumes that loss offsets are immediate, and Table 3 that tax losses are never refunded. Table 4 presents

32 Lund [1987] uses a Monte Cario method to value different Norwegian tax policies on offshore oil development.

33 Although these assumptions may not be particularly representative of U.S. production flelds, Lund's numbers are carefully derived and calibrated. They suffice for the illustrative purposes of our simulations. The valuations can be determined when costs and output are known but changing over time, as in Lund [1987], but the qualitative results are unaffected by this additional complication. The investment cost is only $\$ 500$ million instead of $\$ 700$ million in Lund's paper, because the optimal investment price was implausibly high for $\$ 700 \mathrm{MM}$. This is not surprising, since we assume that lease rights last forever, when in fact they typically expire after a few years, thus lowering the return to waiting. 
the value of the PDA subsidy for a few cases with full loss offsets. We consider several different combinations of the depletion allowance rate, the riskiness of the output price path, and the convenience yield on oil. ${ }^{34}$

The numerical calculations reinforce the earlier results. Consider Table 2 (symmetric taxation). The prices $p_{i}^{*}$ are the minimal prices required for initial investment in the field to be optimal. For all three combinations of risk and convenience yield presented, the minimal investment price decreases as the PDA rate increases; the PDA encourages large investments.

On the other hand, at lower prices, when current production is marginally profitable, the PDA can discourage productive investments. For example, in most cases an increase in the PDA leads to a higher required price before it is optimal to make the fixed cost investment in reopening a closed field. Similarly, increases in the PDA increase the likelihood that firms will "disinvest", by temporarily halting production of operating fields.

Table 4 demonstrates that the PDA provides substantial inframarginal rents, even while encouraging investment at the margin. The PDA subsidy (for $\delta=22 \%$ ) when output price is $\$ 30$ per barrel is $\$ 538$ million for a field with "low costs." The subsidy at a price of $\$ 3.53$ per barrel, essentially equal to marginal cost, is only $\$ 36$ million for a low-cost mine. Viewed another way, the subsidy at $\$ 30 /$ bbl for a "high-cost" field (say, a "deep oil", a tertiary-recovery, or a "heavy oil" field) is only $\$ 276$ million; about half the subsidy to a low-cost, inframarginal project.

\section{Conclusion}

We have shown how to use a stochastic model of intertemporal asset valuation to analyze the effects of tax policies on both asset values and risky investment decisions. In the continuous time framework employed, it is relatively straightforward to model nonlinear or asymmetric tax policies of a sort often encountered; viz, taxes involving kinks, or contingent marginal tax rates.

Analysis of the effects of a corporate income tax with a percentage depletion allowance on the value of mines and decisions to invest in mines provided some interesting results.

34 The convenience yield is $\mu$ in our earlier notation, which determines the risk-adjusted rate of expected price growth, $\overline{\mathbf{\alpha}}=\boldsymbol{r}-\boldsymbol{\mu}$. 
These taxes have the expected effects on asset values, but the distortion to investment decisions can be surprising. The risky investment decision involves a trade-off between the current expected profitability of a mine, and the expected return from waiting until output prices are higher. It is possible that an increase in the corporate tax rate will encourage investment, by reducing the value of waiting to invest relatively more than the reduction in immediate profitability. Similarly, an increase in the PDA subsidy may discourage investment, by increasing the relative return to waiting.

The importance of interactions between uncertainty and nonlinear taxes was also illustrated by observing that a calculation of the PDA subsidy to a project which ignores these interactions will overestimate the value of the subsidy.

Numerical examples were calculated to illustrate the feasibility of the method for relatively complicated dynamic investment and management problems. The numerical examples emphasized the comparative static results by presenting cases in which large, initial production investments in a property would be encouraged by the PDA, but smaller, "operating" investments would be discouraged (i.e, shutdown would be encouraged, and re-opening a closed mine would be discouraged).

All of the analysis in this paper has been of partial equilibrium effects; in particular, the exogenous stochastic price path was unaffected by tax changes. Such an analysis is appropriate for the tax policies of a country in which production of the mineral is smail relative to world output. In a Hotelling-type stochastic general equilibrium model, MacKieMason [1984b] has found that a PDA offered to all firms in an industry tends to increase exploration efforts, but also to lower output prices and increase consumption rates. The effect on total ultimate recovery is ambiguous; in general, the PDA may or may not be a conservationist policy. ${ }^{35}$

Two other recent papers arc concerned with valuing mining assets and investment decisions. Brennan and Schwartz [1986] apply a valuation method derived from a no-arbitrage condition in securities markets. Their approach requires that futures contracts for the commodity be traded with maturities spanning the time horizon of the investment. Since

35 This model involved somewhat diferent cost and geological assumptions, so the results are not directly comparable to those in the present paper. 
minerals futures are generally only traded with maturities of one year or less, applications require restrictive assumptions quite similar to those of the asset pricing equilibrium approach employed in this paper. Brennan and Schwartz [1986] illustrate how to incorporate some taxes in the analysis, but do not investigate the effect of any tax policies on asset values or investment and operating decisions.

Lund [1987] uses Monte Carlo techniques to solve a contingent valuation problem for investments in North Sea oil fields. His analysis emphasizes the effects of the existing Norwegian tax system on the scale of development for an already discovered field. He does not consider the effects of changing tax policies.

Considerable interest has arisen in the application of models of intertemporal asset pricing, as developed in finance literature, to problems of "real" investment. This paper has taken such an approach to the analysis of tax policy effects on asset values and investment and operating decisions, demonstrating both the analytical and numerical tractability of the method for at least some problems. The interesting new results on tax effects show promise for the use of the methods to study other economic problems. 


\section{REFERENCES}

Black, F. and M. Scholes (1973) "The Pricing of Options and Corporate Liabilities," Journal of Political Economy, 81, 637-654.

Bodie, Z. and Rosansky, V. I. (1980) “Risk and Return in Commodity Futures," Financial Analysts Journal, 36, 27-40.

Brennan, M. J. and E. S. Schwartz (1978) "Finite Difference Methods and Jump Processes Arising in the Pricing of Contingent Claims: A Synthesis," Journal of Financial and Quantitative Analysis, , 461-474.

Brennan, M. J. and E. S. Schwartz (1985) "Evaluating Natural Resource Investments," Journal of Business, 58, 135-157.

Bulow, J. and L. H. Summers (1984) "The Taxation of Risky Assets," Journal of Political Economy, 92, 20-39.

Burness, S. H. (1976) "On the Taxation of Nonreplenishable Resources," Journal of Environmental Economics and Management, 3, .

Clark, T. B. (1985) “Retreating to Tax Reform," National Journal, , 1267, 1298-1312.

Constantinides, G. M. (1978) “Market Risk Adjustment in Project Valuation," Journal of Finance, 33, 603-616.

Dasgupta, P. and G. M. Heal (1979) Economic Theory and Exhaustible Resources. Oxford: Cambridge University Press.

Gamponia, V. and R. Mendelsohn (1985) "The Taxation of Exhaustible Resources," Quarterly Journal of Economics, 100, 165-182.

Garnaut, R. and A. Clunies-Ross (1975) "Uncertainty, Risk Aversion and the Taxing of Natural Resource Projects," Economic Journal, 85, 272-287.

Geske, R. and K. Shastri (1985) "Valuation by Approximation: A Comparison of Alternative Option Valuation Techniques," Journal of Financial and Quantitative Analysis, 20, 45-71.

Glen, M. (1985) "Heavy Lobby:. g and Partisan Politicking May Save Oil Industry Tax Preferences," National Journal, , 1008-1012.

Gordon, R. (1985) “Taxation of Corporate Capital Income: Tax Revenues versus Tax Distortions," Quarterly Journal of Economics, 100, 1-27.

Gordon, R. and J. D. Wilson (1986) "Measuring the Efficiency Cost of Taxing Risky Capital Income," NBER Working Paper \#1992. 
Hotelling, H. (1931) "The Economics of Exhaustible Resources," Journal of Political Economy, 39, 137-175.

Lund, D (1987) "Investment, Taxes, and Uncertainty, with Applications to the Norwegian Petroleum Sector," Memorandum No. 1, Department of Economics, University of Oslo, Norway.

MacKie-Mason, J. (1984) "Effects of Federal Tax Policy on Optimal Consumption and Exploration Plans for Exhaustible Natural Resources," Working paper.

MacKie-Mason, J. K. (1984) "Nonlinear Tax Policies and the Risk-Taking Behavior of Firms," Chapter 1, Ph. D. dissertation, MIT.

Majd, S. and S. C. Myers (1984) "Valuing the Government's Tax Claim on Risky Assets," Working Paper, Sloan School of Management, MIT.

Mason, S. P. (1979) "The Numerical Analysis of Risky Coupon Bond Contracts," Harvard Business School Working Paper, \#79-35.

Mason, S. P. and R. C. Merton (1986) "The Role of Contingent Claims Analysis in Corporate Finance," in Recent Advances in Corporate Finance, ed. Altman, A. and M. Subrahmanyam. : , 8-61.

Merton, R. C. (1973) “An Intertemporal CAPM," Econometrica, 41, 867-887.

Merton, R. C. (1973) "Theory of Rational Option Pricing," Bell Journal of Economics, 4, 141-183.

Merton, R. C. (1981) "On the Mathematics and Economic Assumptions of Continuous Time Models," in Financial Economics: Essays in Honor of Paul Cootner, ed. Sharpe, W. F.. Englewood Cliffs, NJ: Prentice-Hall.

Merton, R. C. (1976) "On the Pricing of Contingent Claims and the Modigliani-Miller Theorem," Journal of Financial Economics, 5, 241-250.

Pindyck, R. S. (1980) "Uncertainty and Exhaustible Resource Markets," Journal of Political Economy, 88, 1203-1225.

Rothschild, M. and J. E. Stiglitz (1970) "Increasing Risk I: A Definition," Journal of Economic Theory, 2, 225-243.

Virmani, A. (1986) "Efficiency of Tax-Contract Policies for Natural Resource Rent Collection," World Bank Working Paper, AVD/QJE-008/08.25.86. 


\section{TABLE 1}

Assumptions for Numerical Valuations of Oil Field

Costa

Annual maintenance if closed:

$\$ 5$ million

Unit cost of production:

Cost of opening or closing existing fleld:

$\$ 3.51 / \mathrm{bbl}$

Initial investment cost:

$\$ 1$ million

$\$ 500$ million

Taxes

Corporate income tax rate:

Percentage depletion allowance rate:

Tax treatment of losses:

Prices and Production

Real interest rate:

Convenience yield $(\mu=r-\bar{\alpha})$ :

Instantaneous price variance:

Maximum reserves:

Maximum annual extraction rate:

$50 \%$
varies
varies

$3 \%$
varies
varies
1 million bbl
3 million bbl

\section{TABLE 2}

Asset Values and Investment Decisions: Full Loss Offsets (Field Values in Milion $\mathrm{E}$ )

\begin{tabular}{|c|c|c|c|c|c|c|}
\hline PDA Rate $(\delta)$ & $p_{I}^{*}$ & $V_{o}\left(p_{I}^{*}\right)$ & $p_{o}^{*}$ & $V_{c}\left(p_{0}^{*}\right)$ & $p_{c}^{*}$ & $V_{o}\left(p_{c}^{*}\right)$ \\
\cline { 2 - 7 } Case 1: $\sigma^{2}=.0685, \mu=.04$ & & & & & & \\
$0 \%$ & 21.46 & 1460.6 & 3.83 & 70.2 & 2.62 & 13.4 \\
$15 \%$ & 18.92 & 1482.8 & 4.00 & 107.5 & 2.98 & 39.8 \\
$22 \%$ & 17.39 & 1435.6 & 4.17 & 130.5 & 3.11 & 52.5 \\
& & & & & & \\
Case 2: $\sigma^{2}=.137, \mu=.04$ & & & & & \\
$0 \%$ & 30.02 & 2179.7 & 4.73 & 158.5 & 3.24 & 68.1 \\
$15 \%$ & 26.47 & 2210.9 & 4.54 & 186.4 & 3.24 & 91.1 \\
$22 \%$ & 24.34 & 2146.0 & 4.73 & 218.4 & 3.38 & 109.4 \\
& & & & & & \\
Case 5: $\sigma^{2}=.137, \mu=.08$ & & & & & & \\
$0 \%$ & 24.34 & 1225.2 & 3.68 & 42.3 & 2.22 & 2.5 \\
$15 \%$ & 21.46 & 1241.5 & 3.83 & 64.4 & 2.63 & 15.7 \\
$22 \%$ & 20.57 & 1263.2 & 3.83 & 70.0 & 2.63 & 17.6 \\
\hline
\end{tabular}




\section{TABLE 3}

Asset Values and Investment Decisions: No Loss Ofsets (Field Values in Million $\mathcal{L}$ )

\begin{tabular}{|c|c|c|c|c|c|c|}
\hline PDA Rate $(\delta)$ & $p_{I}^{*}$ & $V_{o}\left(p_{f}^{*}\right)$ & $p_{0}^{*}$ & $V_{e}\left(p_{0}^{*}\right)$ & $p_{c}^{*}$ & $V_{o}\left(p_{c}^{*}\right)$ \\
\hline ase 1: $\sigma^{2}=.0685, \mu=.04$ & & & & & & \\
\hline $0 \%$ & 21.46 & 1460.3 & 4.00 & 78.3 & 3.11 & 30.4 \\
\hline $15 \%$ & 18.92 & 1482.8 & 4.17 & 119.1 & 3.38 & 62.4 \\
\hline $22 \%$ & 17.39 & 1435.4 & 4.17 & 129.7 & 3.24 & 59.5 \\
\hline ase 2: $\sigma^{2}=.137, \mu=.04$ & & & & & & \\
\hline $0 \%$ & 30.02 & 2179.4 & 4.73 & 158.0 & 3.38 & 75.0 \\
\hline $15 \%$ & 26.47 & 2210.5 & 4.73 & 201.1 & 3.53 & 109.6 \\
\hline $22 \%$ & 24.34 & 2145.7 & 4.73 & 218.2 & 3.53 & 110.1 \\
\hline
\end{tabular}

Notes: See Table 2

TABLE 4

Value of the PDA Subsidy (million \$)

PDA. Subsidy Value ( $\delta=22 \%$ v8. $\delta=0 \%$ )

"Low Cost" Field ( $c=\$ 3.51 / \mathrm{bbl})$

$$
\begin{array}{cr}
p_{0}=\$ 30 / \mathrm{bbl} & 538.3 \\
p_{0}=\$ 3.53 / \mathrm{bbl} & 36.6
\end{array}
$$

"High Cost" Field ( $c=\$ 25 / \mathrm{bbl})$

$$
p_{0}=\$ 30 / \mathrm{bbl}
$$

Notes: These valuations assume $\sigma^{2}=.1369$ and $\mu=.04$. 